\title{
Efficacy of an RNA-based multigene assay with core needle biopsy samples for risk evaluation in hormone-positive early breast cancer
}

Jeeyeon Lee ${ }^{1 \dagger}$, Eun Hye Lee ${ }^{2 \dagger}$, Ho Yong Park', Wan Wook Kim', Ryu Kyung Lee ${ }^{1}$, Yee Soo Chae ${ }^{3}$, Soo Jung Lee ${ }^{3}$, Jee-Eun Kim ${ }^{4}$, Byeong-il Kang ${ }^{4}$, Jee Young Park ${ }^{2}$, Ji-Young Park ${ }^{2^{*+}}$ and Jin Hyang Jung ${ }^{1{ }^{*+}}$

\begin{abstract}
Background: Gene expression profiling provides key information for prognosis of breast cancer to establish treatment strategy. However, the genetic assessment should be available before induction of treatment to be useful for clinical practice. To evaluate the reliability of using needle biopsy samples for gene assays, we compared geneexpression profiling results between core needle biopsy (CNB) samples and surgical specimens in breast cancer.

Methods: Thirty-one paired, formalin-fixed, paraffin-embedded CNB and surgical specimen samples were selected from patients with hormone receptor-positive breast cancer. Total RNA was extracted from the samples and the risk classifications based on GenesWell BCT scores were compared.

Results: The BCT scores correlated between CNB samples and surgical specimens of hormone receptor-positive breast cancer (Pearson $r=0.66$ ). The overall concordance rate of risk classification (high/low risk) was 83.9\%. However, when the breast cancer does not contain intratumoral microcalcification, the concordance rate increased as $92.0 \%$. And, when the breast cancer formed a solitary nodule (non-multifocal), the concordance rate increased up to 95.8\%.
\end{abstract}

Conclusion: Risk classification using the GenesWell BCT multigene kit with CNB samples could be considered reliable, when the breast cancer is a solitary nodule without intratumoral microcalcification. Such genetic profiling results should be helpful for establishing a treatment plan for hormone receptor-positive breast cancer before treatment induction.

Keywords: Breast, Carcinoma, Gene, Biopsy

\section{Background}

Breast cancer is a major health problem in women worldwide. It is the most frequent malignancy in women, with nearly 1.4 million new cases and 0.5 million breast cancerrelated deaths [1]. Moreover, the incidence of breast cancer has been increasing gradually, in South Korea, with more than 20\% increase in 2012 compared to 2008 [2]. Among

\footnotetext{
* Correspondence: jyparkmd@knu.ac.kr; jjh01@knu.ac.kr

${ }^{\dagger}$ Jeeyeon Lee and Eun Hye Lee Jung contributed equally to this work.

${ }^{\dagger} \mathrm{Ji}$-Young Park and Jin Hyang Jung contributed equally to this work.

${ }^{2}$ Department of Pathology, School of Medicine, Kyungpook National

University, Kyungpook National University Hospital, Daegu, Republic of Korea

${ }^{1}$ Department of Surgery, School of Medicine, Kyungpook National University,

Kyungpook National University Hospital, Daegu, Republic of Korea

Full list of author information is available at the end of the article
}

newly diagnosed breast cancer patients, about $80 \%$ of have hormone-positive breast cancer with early-staged tumors, and can therefore expect a low risk of recurrence, which means that they may not need adjuvant chemotherapy or radiotherapy [3]. Commercialized multigene kits, such as Oncotype $\mathrm{DX}^{\circ}$, EndoPredict ${ }^{\circ}$, Mammaprint ${ }^{\circ}$, have been approved to estimate the risk of local relapse or distant metastasis [4-6].

Gene expression profiling, which can be used to guide treatment, has emphasized the importance of tumor proliferation as a prognostic factor for hormone receptorpositive breast cancer $[7,8]$. Numerous studies have examined multigene signatures in order to investigate whether the major genes related to tumor proliferation and apoptosis are associated with prognosis [9-13]. This work 
is ongoing; indeed, the companies which produce commercial multigene kits are still searching for additional key factors with greater relevance to breast cancer. Meanwhile, a 9-gene test, GenesWell BCT (Gencurix Inc., Seoul, South Korea), developed domestically in South Korea, has been granted limited approval for estimating risk of distant metastasis within the first 10 years of early, hormone receptor-positive, HER2-negative breast cancer with a prognostic risk score [14]. The present study focused on this kit.

To be useful for clinical practice, gene expression profiling should be available before induction of treatment [15]. However, since multigene kits are usually developed with surgical specimens, and commercial multigene tests have not been extensively studied with needle biopsy samples, they are not comprehensively validated for such use [16-18]. Even if the core needle biopsy (CNB) shows highly accurate results in determining estrogen receptor (ER), progesterone receptor (PR), and HER2 status [19-21], there is a degree of uncertainty in predicting prognosis using multigene test kits with needle biopsy samples prior to initial treatment.

In the present study, we compared the degree of conformity between gene-expression signatures from CNB and surgical specimen samples from the same patient. We used a newly developed multigene test kit (GenesWell $\mathrm{BCT}$ ) to evaluate the reliability of gene-expression profiling from needle biopsy for determining treatment plan in early, hormone-positive breast cancer prior to surgery.

\section{Methods}

\section{Ethical approval}

Informed consent was obtained from all patients and the protocol used in this study was approved by the Institutional Review Board (IRB) Committee of Kyungpook National University Chilgok Hospital, Daegu, Republic of Korea (2018-06-014). And the specific inclusion and exclusion criteria were defined in the approved IRB protocol. The informed consents were obtained by written documents from all patients.

\section{Study population and tissue preparation}

Thirty-six consecutive female patients with early, hormone-positive breast cancer who underwent curative surgery were initially included. However, five of these patients were excluded from our final analysis because of chemotherapy before surgery $(n=1)$, recurrent breast cancer $(n=1)$, inadequate tumor content in specimens $(n=1)$, or negative immunohistochemical expression of ER and PR at confirmatory stain test $(n=2)$.

A total of 31 formalin-fixed, paraffin-embedded (FFPE) samples paired with core needle biopsies and surgical specimens were evaluated. Clinical information used included patients' age, body mass index, clinical and pathologic tumor size, nodal status, pathologic stage, a follow-up period, oncologic outcomes and specific clinical features of breast cancer.

Three or four cores of CNB samples were taken with 16G-core needles for breast mass at diagnosis and surgical specimens were obtained from conventional breast cancer surgery. Both CNB samples and surgical specimens were treated as conventional FFPE tissue sections, and three consecutive $10 \mu \mathrm{m}$-curl type sections were obtained from the FFPE tissue. Tumor volume (\%) was estimated by screening of representative $\mathrm{H}$ \& $\mathrm{E}$ slides and calculated as the ratio between tumor volume and total parenchyma volume, with fat tissues excepted. Each specimen was selected as representative of its tumor block after review by pathologists. All the breast cancers were diagnosed as invasive ductal carcinoma both in CNB and surgical specimen samples.

\section{Histopathologic examination}

Molecular subtyping was based on the immunohistochemical expression of the ER, PR, and HER2/neu gene amplification by silver in situ hybridization (SISH). To define positive expression of ER/PR/HER2, we used the criteria from the ASCO/CAP 2016 guidelines for histopathologic examination.

\section{Total RNA extraction}

Three consecutive FFPE tissue sections with $10 \mu \mathrm{m}$ thickness were prepared for each CNB and the corresponding surgical specimens. We used a fully automated isolation method for total RNA extraction and DNase I treatment from all FFPE tissue sections. This method was based on the manufacturer's manual, and used a tissue preparation system (Siemens Healthcare Diagnostics, Munich, Germany) and VERSANT tissue preparation reagents kit (Siemens Healthcare Diagnostics, Munich, Germany). For each FFPE section, $100 \mu \mathrm{L}$ of extracted total RNA was preserved at $-80^{\circ} \mathrm{C}$.

\section{GenesWell BCT assay and BCT score}

The GenesWell BCT assay was carried out to determine the expression levels ( $\mathrm{Cp}$ values) of six prognostic genes (UBE2C, TOP2A, RRM2, FOXM1, MKI67, and BTN3A2) and three reference genes (CTBP1, CUL1, and UBQLN1). Gene expression levels were measured by quantitative onestep reverse transcription PCR using a QuantiFast Multiplex RT-PCR + R Kit (Qiagen, Hilden, Germany) on a LightCycler 480 II (Roche Diagnostics, Basel, Switzerland).

The BCT score was calculated from the relative expression levels ( $\Delta \mathrm{Cp}$ values) of the six prognostic genes normalized with the three reference genes, in conjunction with clinical information (pathologic tumor size and nodal stage). In the case of core needle biopsies, clinical tumor size and nodal stage were used as clinical information. Each specimen was classified as low or high risk 
of distant relapse based on a pre-defined cutoff BCT score of 4.0, as suggested in a previous study [22]. The concordance between risk classification in surgical and $\mathrm{CNB}$ specimens was identified and the correlation of $\mathrm{BCT}$ score between these two groups was analyzed.

\section{Statistical analysis}

We used Pearson's correlation to compare concordance between groups. Significance was inferred where $P<$ 0.05 . All average values are given as mean $\pm \mathrm{SD}$.

\section{Results}

\section{Patients' characteristics and clinical outcomes}

Among thirty-six paired samples with FFPE tumor sections and CNB samples, thirty-one eligible, paired samples were used in the current study. The mean age of the 31 patients was $58.7 \pm 8.3$ years and their mean body mass index (BMI) was $24.6 \pm 3.3$. The mean clinical and pathologic tumor sizes were $1.4 \pm 0.7 \mathrm{~cm}$ and $1.5 \pm 0.5$ $\mathrm{cm}$, respectively. Sever cases (22.6\%) showed multifocality in preoperative imaging findings and final pathologic report. Pathologic tumor stages were as follows: IA $(n=$ $23,74.2 \%)$; IB $(n=1,3.2 \%)$; IIA $(n=7,22.6 \%)$. There were two cases $(6.5 \%)$ of locoregional recurrence during $40.2 \pm 28.6$ months of mean follow-up period (Table 1 ).

\section{Comparison of the tumor volume and BCT score}

We expressed tumor volume as the percentage of total parenchymal tissue volume occupied by tumor. Mean tumor volume (\%) in CNB and surgical specimen samples was $60.1 \pm 21.7$ and $39.8 \pm 16.7$, respectively. There were four cases of pathologic N1 stage, for which the clinical stage was N0 (Table 2). And the BCT scores were compared between $\mathrm{CNB}$ samples and surgical specimens.

Table 1 Characteristics of thirty-one breast cancer cases for which multigene tests were performed on both core needle biopsy samples and surgical specimens

\begin{tabular}{ll}
\hline Variables & $n=31$ \\
\hline Mean age (years, \pm SD) & $58.7 \pm 8.3$ \\
Mean body mass index $\left(\mathrm{kg} / \mathrm{m}^{2}, \pm \mathrm{SD}\right)$ & $24.6 \pm 3.3$ \\
Mean clinical tumor size $(\mathrm{cm}, \pm \mathrm{SD})$ & $1.4 \pm 0.7$ \\
Mean pathological tumor size $(\mathrm{cm}, \pm \mathrm{SD})$ & $1.5 \pm 0.5$ \\
Cases of multifocality $(\mathrm{n}, \%)$ & $7(22.6)$ \\
Containing microcalcification $(\mathrm{n}, \%)$ & $6(19.4)$ \\
Pathologic tumor stage $(\mathrm{n}, \%)$ & \\
$\quad$ IA & $23(74.2)$ \\
IB & $1(3.2)$ \\
$\quad$ IA & $7(22.6)$ \\
Mean follow-up period (months, \pm SD) & $40.2 \pm 28.6$ \\
Locoregional recurrence ( $\mathrm{n}, \%)$ & $2(6.5)$ \\
\hline
\end{tabular}

\section{Correlation of gene expression in paired samples}

Gene expression $(\Delta \mathrm{Ct})$ values in $\mathrm{CNB}$ samples and surgical specimens were correlated, with Pearson coefficients ranging from 0.20 to 0.99 . The mean overall $\Delta \mathrm{Ct}$ value was $0.76 \pm 0.24$ (Fig. 1). Five case (\#17, \#23, \#26, \#30, \#36) showed different risk classification between CNB and surgical samples (Fig. 2). The overall correlation rate of risk classification between $\mathrm{CNB}$ samples and surgical specimens was $83.9 \%$. However, the concordance rate was higher as $92.0 \%$, when the breast cancer was non-microcalcified lesion and $95.8 \%$, when the breast cancer formed a solitary nodule (Table 3 ).

\section{Discussion}

Although the incidence of breast cancer is increasing, its mortality rate is declining as a result of more widespread screening allowing earlier diagnosis, and advances in treatment [23, 24]. However, the higher long-term survival rate of breast cancer may increase the probability of locoregional recurrence or distant metastasis. The treatment options for breast cancer include not only surgery but also other adjuvant treatments, including invasive treatment such as chemotherapy or radiotherapy, and less invasive treatment such as hormone or target therapy. Although the invasive treatments are unnecessary for several subgroups of breast cancer which show better prognosis, it is hard to distinguish those subgroups with conventional diagnostic methods $[25,26]$.

Genomic profiling technologies have become an effective diagnostic method to predict clinical course of breast cancer and are helpful for making decisions relating to the tailoring of its treatment cancer [15, 21, 22, 27]. Based on multigene assays, patients with better prognosis may avoid invasive treatments such as chemotherapy or radiotherapy and their associated side effects. Several commercialized multigene predictors aimed at providing genetic information to enhance prognostic medical decisions in breast cancer have been developed recently cancer [28, 29]. One example is the microarray-based 70-gene assay, MammaPrint ${ }^{\circ}$, launched in 2002 by the Netherlands Cancer Institute in Amsterdam. Another is the a 21-gene multiplex prognostic and predictive RT-PCR assay oncotype $\mathrm{DX}^{\mathrm{m}}$, which was introduced in 2004 with the Trial Assigning Individualized Options for Treatment (TAILORx) sponsored by the National Cancer Institute. Later, in 2011, the first RNA-based prognostic test, EndoPredict ${ }^{\circ}$, was introduced to predict the distant recurrence of ER-positive, HER2-negative breast cancer $[4,28]$. These commercialized multigene assay kits were developed using FFPE or freshly frozen tissue obtained from surgery. Therefore, their development was limited by a lack of genetic information obtained prior to treatment. To overcome this limitation, studies have been conducted to confirm a 
Table 2 Clinical and pathological tumor size, volume, and nodal stage of thirty-one paired samples

\begin{tabular}{|c|c|c|c|c|c|c|c|c|}
\hline \multirow[t]{2}{*}{ No. } & \multirow[t]{2}{*}{ Age } & \multicolumn{3}{|c|}{ Core needle biopsy } & \multicolumn{3}{|c|}{ Surgical specimen } & \multirow{2}{*}{ Clinical characteristics of breast cancer } \\
\hline & & $\begin{array}{l}\text { Tumor } \\
\text { volume (\%) }\end{array}$ & $\begin{array}{l}\text { Clinical tumor } \\
\text { size }(\mathrm{cm})\end{array}$ & $\mathrm{cN}$ stage & $\begin{array}{l}\text { Tumor } \\
\text { volume (\%) }\end{array}$ & $\begin{array}{l}\text { Pathologic tumor } \\
\text { size }(\mathrm{cm})\end{array}$ & $\mathrm{pN}$ stage & \\
\hline$\# 1$ & 50 's & 70 & 1.1 & 0 & 20 & 1.3 & 0 & Solitary nodule \\
\hline \#2 & 60 's & 98 & 2.8 & 0 & 50 & 2.8 & 0 & Solitary nodule \\
\hline \#4 & 50 's & 60 & 3.2 & 0 & 35 & 3.2 & 0 & $\begin{array}{l}\text { Multifocal/multicentric nodules, Containing } \\
\text { microcalcifications }\end{array}$ \\
\hline \#5 & 60 's & 30 & 2.5 & 0 & 60 & 2.2 & 0 & $\begin{array}{l}\text { Multifocal/multicentric nodules, Containing } \\
\text { microcalcifications }\end{array}$ \\
\hline \#7 & 50 's & 70 & 1.4 & 0 & 30 & 1.6 & 0 & Solitary nodule \\
\hline$\# 8$ & 40 's & 50 & 1.5 & 0 & 20 & 1.1 & 0 & Solitary nodule \\
\hline \#9 & $40^{\prime} \mathrm{s}$ & 80 & 1.5 & 0 & 25 & 1.6 & 1 & Solitary nodule \\
\hline$\# 10$ & 40 's & 80 & 1.0 & 0 & 40 & 1.5 & 0 & Solitary nodule \\
\hline$\# 11$ & 60 's & 40 & 2.0 & 0 & 50 & 1.8 & 0 & Solitary nodule \\
\hline$\# 13$ & 70 's & 90 & 3.0 & 0 & 30 & 2.2 & 0 & Solitary nodule \\
\hline \#15 & 60 's & 70 & 1.8 & 0 & 30 & 1.9 & 0 & Solitary nodule \\
\hline \#16 & 40 's & 20 & 1.2 & 0 & 50 & 1.5 & 0 & $\begin{array}{l}\text { Multifocal/multicentric nodules, Containing } \\
\text { microcalcifications }\end{array}$ \\
\hline$\# 17$ & 50 's & 15 & 1.1 & 0 & 20 & 0.7 & 0 & Solitary nodule \\
\hline$\# 19$ & 60 's & 60 & 1.9 & 0 & 40 & 1.4 & 0 & Solitary nodule \\
\hline \#20 & 60 's & 40 & 0.3 & 0 & 40 & 1.3 & 0 & Solitary nodule \\
\hline \#21 & 50 's & 70 & 0.9 & 0 & 60 & 1.2 & 0 & Solitary nodule \\
\hline \#22 & 60 's & 60 & 1.2 & 0 & 40 & 1.4 & 0 & Solitary nodule \\
\hline \#23 & 60 's & 80 & 0.9 & 0 & 60 & 1.1 & 1 & $\begin{array}{l}\text { Multifocal/multicentric nodules, Containing } \\
\text { microcalcifications }\end{array}$ \\
\hline$\# 24$ & 60 's & 50 & 1.8 & 0 & 80 & 1.5 & 0 & Solitary nodule \\
\hline$\# 25$ & 50 's & 60 & 1 & 0 & 10 & 1.4 & 1 & Solitary nodule \\
\hline$\# 26$ & 50 's & 60 & 2 & 0 & 60 & 1.2 & 0 & Multifocal/multicentric nodules \\
\hline \#27 & 60 's & 80 & 0.9 & 0 & 60 & 1.1 & 0 & Solitary nodule \\
\hline$\# 28$ & 60 's & 40 & 0.5 & 0 & 30 & 0.8 & 0 & Solitary nodule \\
\hline \#29 & 50 's & 80 & 1.1 & 0 & 10 & 1.4 & 0 & Solitary nodule \\
\hline \#30 & 60 's & 40 & 1.6 & 0 & 40 & 1.8 & 0 & $\begin{array}{l}\text { Multifocal/multicentric nodules, Containing } \\
\text { microcalcifications }\end{array}$ \\
\hline \#31 & 70 's & 50 & 1 & 0 & 50 & 0.9 & 0 & Solitary nodule \\
\hline \#32 & 70 's & 60 & 1.25 & 0 & 50 & 1.6 & 1 & Solitary nodule \\
\hline \#33 & 60 's & 60 & 1.5 & 0 & 40 & 1.3 & 0 & Solitary nodule \\
\hline \#34 & 50 's & 20 & 1 & 0 & 20 & 0.8 & 0 & Solitary nodule \\
\hline \#35 & 50 's & 70 & 0.7 & 0 & 50 & 1.1 & 0 & Solitary nodule \\
\hline \#36 & $50^{\prime} \mathrm{s}$ & 80 & 0.8 & 0 & 40 & 1.1 & 0 & $\begin{array}{l}\text { Multifocal/multicentric nodules, Containing } \\
\text { microcalcifications }\end{array}$ \\
\hline
\end{tabular}

satisfactory level of correlation between results obtained from needle biopsy tissue and surgical specimens [15, 19-21].

Adding further complexity, previous gene expression profiling studies have shown discordant results between different ethnicities [30-32]. GenesWell BCT was developed using six prognostic genes including five proliferative genes (UBE2C, TOP2A, RRM2, FOXM1, and MKI67), one gene involved in the immune system (BTN3A2) and three reference genes (CTBP1, CUL1, UBQLN1). These genes were selected from public microarray gene expression data, and the reliability of the BCT score produced by GenesWell BCT was validated in an independent cohort of Koreans [22].

Because this product was developed especially for ER +, HER2- breast cancer patients, who show little benefit 


\begin{tabular}{cc}
\hline No. of patients & $\Delta$ Ct value correlation \\
\hline 1 & 0.98 \\
2 & 0.65 \\
4 & 0.95 \\
5 & 0.89 \\
7 & 0.96 \\
8 & 0.58 \\
9 & 0.94 \\
10 & 0.99 \\
11 & 0.93 \\
13 & 0.65 \\
15 & 0.77 \\
16 & 0.88 \\
17 & 0.88 \\
19 & 0.73 \\
20 & 0.85 \\
21 & 0.37 \\
22 & 0.08 \\
23 & 0.98 \\
24 & 0.93 \\
25 & 0.94 \\
26 & 0.90 \\
27 & 0.90 \\
28 & 0.54 \\
29 & 0.98 \\
30 & 0.83 \\
31 & 0.81 \\
32 & 0.20 \\
33 & 0.35 \\
34 & 0.60 \\
35 & 0.67 \\
36 & 0.71 \\
\hline Mean $( \pm$ SD $)$ & $0.76 \pm 0.24$ \\
\hline & \\
\hline & \\
\hline &
\end{tabular}

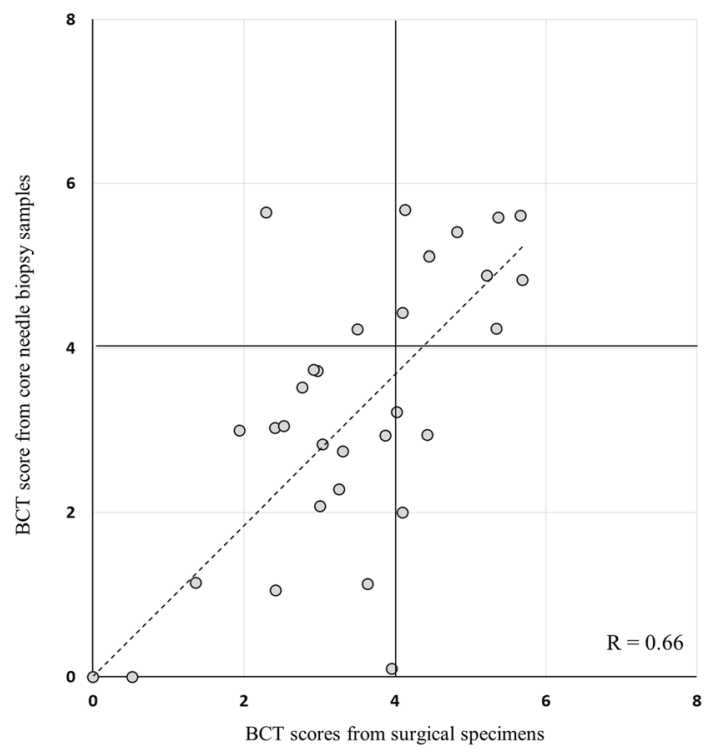

Fig. 1 Correlations of gene expression ( $\Delta$ Ct value) and BCT score between paired core biopsy samples and surgical specimens in each patient. Mean correlation value was $0.76 \pm 0.24$ and four cases showed different risk classification between two samples

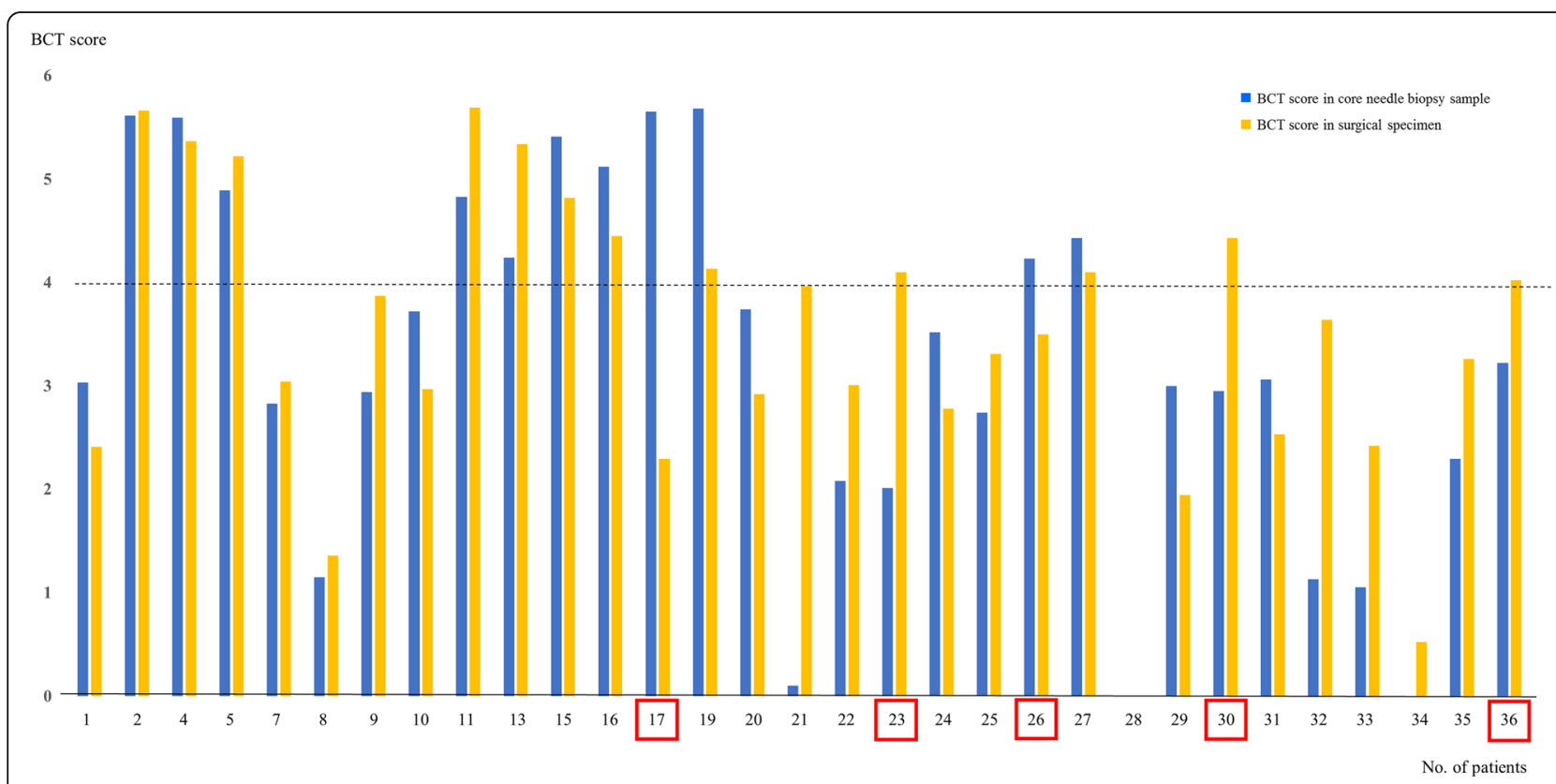

Fig. 2 Correlation of absolute BCT scores between the paired core needle biopsy and surgical specimen samples. Based on a threshold BCT score of 4 , the risk classification of five patients (no. 17, 23, 26, 30, 36) showed discordance between needle biopsy samples and surgical specimens 
Table 3 Concordance of risk classification between core needle biopsy samples and surgical specimens

\begin{tabular}{|c|c|c|c|c|c|}
\hline & \multirow{2}{*}{$\begin{array}{l}\text { Core needle biopsy } \\
\text { sample }(n, \%)\end{array}$} & \multicolumn{2}{|c|}{ Surgical specimen ( $n, \%)$} & \multirow[t]{2}{*}{ Total } & \multirow{2}{*}{$\begin{array}{l}\text { Concordance } \\
\text { rate (\%) }\end{array}$} \\
\hline & & Low risk & High risk & & \\
\hline \multirow[t]{3}{*}{ All breast cancers } & Low risk & $17(54.8)$ & $3(9.7)$ & $20(64.5)$ & \multirow[t]{3}{*}{83.9} \\
\hline & High risk & $2(6.5)$ & $9(29.0)$ & $11(35.5)$ & \\
\hline & Total & $19(61.3)$ & $12(38.7)$ & $31(100.0)$ & \\
\hline \multirow[t]{3}{*}{ Non-calcified breast cancers } & Low risk & $17(68.0)$ & $1(4.0)$ & $18(72.0)$ & \multirow[t]{3}{*}{92.0} \\
\hline & High risk & $1(4.0)$ & $6(24.0)$ & $7(28.0)$ & \\
\hline & Total & $18(72.0)$ & $7(28.0)$ & $25(100.0)$ & \\
\hline \multirow[t]{3}{*}{ Solitary (Non-multifocal) breast cancers } & Low risk & $17(70.8)$ & 0 & $17(70.8)$ & \multirow[t]{3}{*}{95.8} \\
\hline & High risk & $1(4.2)$ & $6(25.0)$ & $7(29.2)$ & \\
\hline & Total & $18(75.0)$ & $6(25.0)$ & $24(100.0)$ & \\
\hline
\end{tabular}

from chemotherapy, chemotherapy can be omitted for this group when the result indicates low risk. However, the genetic information should be obtained before treatment is started.

Recently, most breast cancer is detected by screening image and diagnosed at an early stage [33, 34]. To confirm diagnosis, ultrasound-guided needle biopsy is more popular than excision. Usually three or four cores are obtained using a needle biopsy kit and tumor characteristics are analyzed with immunohistochemical staining as well as examined visually for presence of cancer cells. However, breast cancer is known to be particularly heterogeneous within the tumor, and results can differ between operators. Furthermore, 10-20\% of immunohistochemical staining results disagree between needle biopsy samples and surgical specimens in assessment of molecular subtype [17, 35]. Therefore, when the breast cancer is multifocal lesion or containing heterogenous materials, including microcalcifications, the tissue concordance would be decreased between needle biopsy samples and surgical specimens.

In the present study, we investigated whether the GenesWell BCT multigene test is suitable for CNB samples in addition to surgical specimens. The samples were obtained from areas in which at least 30\% of total tissue volume was tumorous, if possible. The overall concordance rate that we observed between $\mathrm{CNB}$ and surgical specimens was $83.9 \%$, which was similar or lower than other commercialized multigene kits. However, when the breast tumor showed an imaging finding of solitary nodule without microcalcification, the concordance rates were higher as 92.0 and $95.8 \%$, respectively.

The current study aimed at validating the use of the GenesWell BCT kit to improve prognostic prediction in hormone-positive breast cancer, in order to establish treatment plans prior to initial treatment. With this aim in mind, two limitations should be noted. First, the small number of paired samples cautions strong conclusions, in particular inference to other subtypes of breast cancer. Even if we conducted the study with thirty-one paired samples of hormone positive breast cancer, it is still a small study. Therefore, the further study would be necessary to validate the results and provide the stronger evidences with reproduction of results. However, it is notable that in our thirty-one paired samples of hormone-positive breast cancer, we observed a very high concordance rate between needle biopsy samples and surgical specimens when the breast cancer is not multifocal, without containing microcalcifications. The second limitation relates to the oncologic conditions of gene profiling using GenesWell BCT. Although the actual $\mathrm{BCT}$ scores were developed with pathologic tumor size and nodal status, in the present study we used clinical tumor size and nodal status for obtaining BCT scores from biopsy samples. However, based on preoperative breast magnetic resonance (MR) images showing quite a high concordance rate between clinical and pathologic tumor size in early breast cancer [36, 37], it is reasonable to apply clinical tumor size for assessing BCT score before treatment. Because we also evaluated tumor size with preoperative breast MR, the clinical and pathologic staging we recorded were identical in most cases. Although there was one case in which sentinel lymph node biopsy was omitted in order to shorten the operative time because of the patient's severe underlying disease, she has not experienced locoregional recurrence or distant metastasis during the follow-up period. Therefore, the authors regarded this case as clinically and pathologically N0 stage.

\section{Conclusion}

The correlations of risk classification obtained from the GenesWell BCT multigene kit between CNB samples and surgical specimens in hormone positive breast cancer was relatively low, but not much inferior to other proven commercialized genetic profiling products. However, the multigene tests were performed in cases of solitary breast cancer without microcalcification, the concordance rate was much higher. This data supports the possibility of using the risk 
scores obtained to help establish a treatment plan before starting initial breast cancer treatment, especially for a solitary nodule of breast cancer without microcalcifications.

\section{Abbreviations}

BCT: Breast cancer test; BMI: Body mass index; CNB: Core needle biopsy; ER: Estrogen receptor; FFPE: Formalin-fixed, paraffin-embedded; MR: Magnetic resonance; PR: Progesterone receptor; SISH: Silver in situ hybridization

\section{Funding}

This research was supported by a grant of the Korea Health Technology R\&D Project through the Korea Health Industry Development Institute (KHIDI), funded by the Ministry of Health \& Welfare, Republic of Korea (H117C1142). The funder had no role in the design of the study and collection, analysis, and interpretation of data and in writing the manuscript.

\section{Availability of data and materials}

The datasets generated and/or analyzed during the current study are not publicly available due to the data is in company's possession. But, they are available from the corresponding author on reasonable request.

\section{Authors' contributions}

Guarantor of the integrity of the study: JL, Study concepts: HYP, Study design: JHJ, WWK, Definition of intellectual content: JL, EHL, Literature research: RKL, SJL, Clinical studies: JYP, J-YP, EHL, J-EK, BK, Data acquisition: WWK, YSC, SJL, Data analysis: J-EK, BK, JL, Manuscript preparation: JL, J-EK, Manuscript editing: JHJ, Manuscript review: YSC, JHJ. All authors have read and approved the manuscript.

\section{Ethics approval and consent to participate}

Informed consent was obtained from all patients and the protocol used in this study was approved by the Institutional Review Board (IRB) Committee of Kyungpook National University Chilgok Hospital, Daegu, Republic of Korea (2018-06-014). And the specific inclusion and exclusion criteria were defined in the approved IRB protocol. The informed consents were obtained by written documents from all patients.

\section{Consent for publication}

Not applicable.

\section{Competing interests}

The authors declare that they have no competing interests.

\section{Publisher's Note}

Springer Nature remains neutral with regard to jurisdictional claims in published maps and institutional affiliations.

\section{Author details}

'Department of Surgery, School of Medicine, Kyungpook National University, Kyungpook National University Hospital, Daegu, Republic of Korea.

${ }^{2}$ Department of Pathology, School of Medicine, Kyungpook National University, Kyungpook National University Hospital, Daegu, Republic of Korea. ${ }^{3}$ Department of Hemato-Oncology, School of Medicine, Kyungpook National University, Kyungpook National University Hospital, Daegu, Republic of Korea. ${ }^{4}$ R\&D Center, Gencurix Inc., Seoul, Republic of Korea.

Received: 14 September 2018 Accepted: 12 April 2019

Published online: 25 April 2019

\section{References}

1. Tao Z, Shi A, Lu C, Song T, Zhang Z, Zhao J. Breast cancer: epidemiology and etiology. Cell Biochem Biophys. 2015;72(2):333-8.

2. Park EH, Min SY, Kim Z, Yoon CS, Jung KW, Nam SJ, et al. Basic facts of breast cancer in Korea in 2014: the 10-year overall survival progress. J Breast Cancer. 2017:20(1):1-11.

3. Bardia A, Hurvitz S. Targeted therapy for premenopausal women with HR+, HER2- advanced breast cancer: focus on special considerations and latest advances. Clin Cancer Research. 2018;24:2506-18.
4. Filipits $M$, Rudas $M$, Jakesz R, Dubsky P, Fitzal F, Singer CF, et al. A new molecular predictor of distant recurrence in ER-positive, HER2-negative breast cancer adds independent information to conventional clinical risk factors. Clin Cancer Res. 2011;17(18):6012-20.

5. Rayhanabad JA, Difronzo LA, Haigh PI, Romero L. Changing paradigms in breast cancer management: introducing molecular genetics into the treatment algorithm. Am Surg. 2008;74(10):887-90.

6. Sapino A, Roepman P, Linn SC, Snel MH, Delahaye L, van den Akker J, et al. MammaPrint molecular diagnostics on formalin-fixed, paraffin-embedded tissue. J Mol Diagn. 2014;16(2):190-7.

7. Reis-Filho JS, Pusztai L. Gene expression profiling in breast cancer: classification, prognostication, and prediction. Lancet. 2011;378(9805):1812-23.

8. Kittaneh M, Montero AJ, Gluck S. Molecular profiling for breast cancer: a comprehensive review. Biomark Cancer. 2013;5:61-70.

9. Yersal O, Barutca S. Biological subtypes of breast cancer: prognostic and therapeutic implications. World J Clin Oncol. 2014;5(3):412-24.

10. Wee Y, Liu Y, Lu J, Li X, Zhao M. Identification of novel prognosis-related genes associated with cancer using integrative network analysis. Sci Rep. 2018;8(1):3233.

11. Jonsdottir K, Assmus J, Slewa A, Gudlaugsson E, Skaland I, Baak JP, et al. Prognostic value of gene signatures and proliferation in lymph-nodenegative breast cancer. PLoS One. 2014;9(3):e90642.

12. Zins K, Heller G, Mayerhofer M, Schreiber M, Abraham D. Differential prognostic impact of interleukin-34 mRNA expression and infiltrating immune cell composition in intrinsic breast cancer subtypes. Oncotarget. 2018;9(33):23126-48.

13. Liu MC, Pitcher BN, Mardis ER, Davies SR, Friedman PN, Snider JE, et al. PAM50 gene signatures and breast cancer prognosis with adjuvant anthracycline- and taxane-based chemotherapy: correlative analysis of C9741 (Alliance). NPJ Breast Cancer. 2016;2.

14. Kim JKB, Bae S, Han S, Jun A, Han J, Cho M, Choi Y, Lee J, Moon Y. An analytical validation of the GenesWellTM BCT multigene prognostic test in patients with early breast cancer. Korean J Clin Lab Sci. 2017:49:79-87.

15. Symmans WF, Ayers M, Clark EA, Stec J, Hess KR, Sneige N, et al. Total RNA yield and microarray gene expression profiles from fine-needle aspiration biopsy and core-needle biopsy samples of breast carcinoma. Cancer. 2003;97(12):2960-71.

16. Zanetti-Dallenbach $R$, Vuaroqueaux V, Wight E, Labuhn M, Singer G, Urban P, et al. Comparison of gene expression profiles in core biopsies and corresponding surgical breast cancer samples. Breast Cancer Res. 2006;8(4):R51.

17. Muller BM, Brase JC, Haufe F, Weber KE, Budzies J, Petry C, et al. Comparison of the RNA-based EndoPredict multigene test between core biopsies and corresponding surgical breast cancer sections. J Clin Pathol. 2012;65(7):660-2.

18. Drubin D, Smith JS, Liu W, Zhao W, Chase GA, Clawson GA. Comparison of cryopreservation and standard needle biopsy for gene expression profiling of human breast cancer specimens. Breast Cancer Res Treat. 2005;90(1):93-6

19. You K, Park S, Ryu JM, Kim I, Lee SK, Yu J, et al. Comparison of core needle biopsy and surgical specimens in determining intrinsic biological subtypes of breast cancer with immunohistochemistry. J Breast Cancer. 2017;20(3):297-303.

20. Chen X, Yuan Y, Gu Z, Shen K. Accuracy of estrogen receptor, progesterone receptor, and HER2 status between core needle and open excision biopsy in breast cancer: a meta-analysis. Breast Cancer Res Treat. 2012;134(3):957-67.

21. Chen X, Sun L, Mao Y, Zhu S, Wu J, Huang O, et al. Preoperative core needle biopsy is accurate in determining molecular subtypes in invasive breast cancer. BMC Cancer. 2013;13:390.

22. Gong G, Kwon MJ, Han J, Lee HJ, Lee SK, Lee JE, et al. A new molecular prognostic score for predicting the risk of distant metastasis in patients with HR+/HER2- early breast cancer. Sci Rep. 2017;7:45554.

23. Bodai BI, Tuso P. Breast cancer survivorship: a comprehensive review of long-term medical issues and lifestyle recommendations. Perm J. 2015; 19(2):48-79.

24. Narod $S A$, lqbal J, Miller $A B$. Why have breast cancer mortality rates declined? J Cancer Policy. 2015;5:8-17.

25. Sinn P, Aulmann S, Wirtz R, Schott S, Marme F, Varga Z, et al. Multigene assays for classification, prognosis, and prediction in breast cancer: a critical review on the background and clinical utility. Geburtshilfe Frauenheilkd. 2013;73(9):932-40.

26. Dai X, Li T, Bai Z, Yang Y, Liu X, Zhan J, et al. Breast cancer intrinsic subtype classification, clinical use and future trends. Am J Cancer Res. 2015;5(10): 2929-43.

27. Kwon MJ, Oh E, Lee S, Roh MR, Kim SE, Lee Y, et al. Identification of novel reference genes using multiplatform expression data and their validation for quantitative gene expression analysis. PLoS One. 2009;4(7):e6162. 
28. Varga Z, Sinn P, Fritzsche F, von Hochstetter A, Noske A, Schraml P, et al. Comparison of EndoPredict and Oncotype DX test results in hormone receptor positive invasive breast cancer. PLoS One. 2013;8(3):e58483.

29. Ross JS, Hatzis C, Symmans WF, Pusztai L, Hortobagyi GN. Commercialized multigene predictors of clinical outcome for breast cancer. Oncologist. 2008;13(5):477-93.

30. Prat A, Parker JS, Fan C, Cheang MC, Miller LD, Bergh J, et al. Concordance among gene expression-based predictors for ER-positive breast cancer treated with adjuvant tamoxifen. Ann Oncol. 2012;23(11):2866-73.

31. Na KY, Kim KS, Lee JE, Kim HJ, Yang JH, Ahn SH, et al. The 70-gene prognostic signature for korean breast cancer patients. J Breast Cancer. 2011;14(1):33-8.

32. Ishitobi M, Goranova TE, Komoike Y, Motomura K, Koyama H, Glas AM, et al. Clinical utility of the 70-gene MammaPrint profile in a Japanese population. Jpn J Clin Oncol. 2010:40(6):508-12

33. Salem DS, Kamal RM, Mansour SM, Salah LA, Wessam R. Breast imaging in the young: the role of magnetic resonance imaging in breast cancer screening, diagnosis and follow-up. J Thorac Dis. 2013;5(Suppl 1):S9-s18.

34. Ontario HQ. Cancer screening with digital mammography for women at average risk for breast cancer, magnetic resonance imaging (MRI) for women at high risk: an evidence-based analysis. Ont Health Technol Assess Ser. 2010;10(3):1-55.

35. Ensani F, Omranipour R, Jahanzad I, Jafari A, Nafarzadeh S, Aminishakib P. The core needle and surgical biopsy concordance to detect estrogen, progesterone, and Her-2 receptors in breast cancer: a comparative study. Iran J Pathol. 2017:12(3):202-8.

36. Grimsby GM, Gray R, Dueck A, Carpenter S, Stucky CC, Aspey H, et al. Is there concordance of invasive breast cancer pathologic tumor size with magnetic resonance imaging? Am J Surg. 2009;198(4):500-4.

37. Choi WJ, Cha JH, Kim HH, Shin HJ, Chae EY. The accuracy of breast MR imaging for measuring the size of a breast cancer: analysis of the histopathologic factors. Clin Breast Cancer. 2016;16(6):e145-e52

Ready to submit your research? Choose BMC and benefit from:

- fast, convenient online submission

- thorough peer review by experienced researchers in your field

- rapid publication on acceptance

- support for research data, including large and complex data types

- gold Open Access which fosters wider collaboration and increased citations

- maximum visibility for your research: over $100 \mathrm{M}$ website views per year

At $\mathrm{BMC}$, research is always in progress.

Learn more biomedcentral.com/submissions 